\title{
Numerical Simulation of Seepage and Deformation in Excavation of a Deep Foundation Pit under Water-Rich Fractured Intrusive Rock
}

\author{
Changfeng Yuan $\mathbb{D}^{1},{ }^{1}$ Zhenhui Hu, ${ }^{1}$ Zhen Zhu $\mathbb{D}^{1},{ }^{1}$ Zijin Yuan, ${ }^{2}$ Yanxiang Fan, ${ }^{2}$ Hui Guan, ${ }^{3}$ \\ and Liang $\mathrm{Li}$ (iD ${ }^{1}$
}

${ }^{1}$ School of Civil Engineering, Qingdao University of Technology, Qingdao 266033, China

${ }^{2}$ Qingdao Tengyuan Design Office Co. Ltd., Qingdao 266100, China

${ }^{3}$ China Railway 25th Bureau Group Co. Ltd., Qingdao 266101, China

Correspondence should be addressed to Zhen Zhu; zhuzhen@qut.edu.cn

Received 24 December 2020; Revised 19 January 2021; Accepted 1 February 2021; Published 13 February 2021

Academic Editor: Feng Xiong

Copyright (c) 2021 Changfeng Yuan et al. This is an open access article distributed under the Creative Commons Attribution License, which permits unrestricted use, distribution, and reproduction in any medium, provided the original work is properly cited.

\begin{abstract}
Water is one of the major risk sources in the excavation of deep-large foundation pits in a water-rich area. The presence of intrusive broken diorite porphyrite in the stratum aggravates the risk level of deep foundation pits. Based on a geological survey report and design documents of parameter information, MIDAS/GTS software was used to perform the numerical simulation of an engineering example of a deep foundation pit project of ultradeep and water-rich intrusion into the broken rock station of subway line 4 in a city. The simulation results show the characteristics of seepage path evolution, seepage aggregation areas and points, and the effect of seepage on the deformation of a deep foundation pit during the whole construction of this deep foundation pit. The results show that with the precipitation-excavation of the deep foundation pit, the pore water pressure at the bottom of the foundation pit follows a distribution of three "concave" shapes. High-permeability pressure zones are found around the foundation pit, intruding broken diorite porphyrite zones, and middle coarse sand zones. With further excavation of the foundation pit, the seepage pressure in the middle part of the foundation pit gradually decreases, and the two "concave" distributions in the middle gradually merge together. After excavation to the bottom of the pit, the pore water pressure at the bottom is distributed in two asymmetrical "concave" shapes, and the maximum peak of pore water pressure is found at the intrusion of fractured porphyrites prone to water inrush. The four corners of the foundation pit are prone to form seepage accumulation zones; therefore, suffosion and piping zones are formed. The surface settlement caused by excavation is found to be the largest along the longitudinal axis of the deep foundation pit, whereas the largest deformation is found near the foundation pit side in the horizontal axis direction of the foundation pit. With the excavation of the deep foundation pit, the diaphragm wall converges to the foundation pit with the maximum deformation reaching about $25 \mathrm{~mm}$. After the first precipitation-excavation of the deep foundation pit to the silty clay and the bottom of the pit with the largest uplift, with further precipitation-excavation of the deep foundation pit, the uplift at the bottom of the deep foundation pit changes only slightly.
\end{abstract}

\section{Introduction}

Disasters of deep foundation pits are mostly related to the improper control of groundwater. In recent years, with the shortage of urban land resources, more and more deep foundation pit projects have been undertaken, and the excavation depth has generally reached more than $20 \mathrm{~m}$. At the same time, the number of deep foundation pits larger than $30 \mathrm{~m}$ is also increasing. Water problems are encountered as the foundation pit continues to deepen; in particular, groundwater control is the focus of research in some deep foundation pit projects when located in water-rich fractured rock areas. At present, mainly two methods are available to control confined water, i.e., water stop curtain partition and pumping 
decompression [1]. Both the abovementioned methods require a water seepage path and evolution trend along with excavation to obtain accurate information about the design to ensure project safety. Regarding the seepage and deformation characteristics of deep foundation pits, studies [2-28] have shown that the seepage velocity of a foundation pit first increases and then decreases with the increase in the waterproof curtain depth and finally becomes stable. The hydraulic gradient is distributed at the bottom of the pit in a "concave" shape. Hydraulic gradient is the largest at the corner of the foundation pit, where it is prone to seepage failure. For the excavation of deep foundation pits under the influence of precipitation and excess pore water pressure, the change in permeability coefficient significantly affects the foundation pit floor heave, and the change in permeability coefficient significantly affects the foundation pit. The optimum bottom heave insertion ratio of the underground diaphragm wall is approximately 0.5 ; the maximum performance can be reached under this condition. If the diaphragm wall is too deep, the effect on the uplift resistance of the foundation pit will be reduced. A linear relationship is obtained between the maximum horizontal displacement of the underground diaphragm wall and excavation depth. As the depth of phreatic water level increases, the maximum surface settlement and maximum pile displacement on both sides of the pit will decrease linearly. In the bottom layer of foundation pit excavation under seepage condition, the soil around the pile will also rebound due to water pressure. The soil's rebound amount is higher than the pile's rebound amount due to the water pressure caused by large displacement rebound of soil around the pile. Although great achievements have been made in this research, the variability of geotechnical engineering in time and space makes each specific deep foundation pit project have its own characteristics; therefore, it is necessary to perform focused research in the abovementioned aspects for deep large foundation pits with different geological conditions.

The seepage and deformation evolution trends of deep foundation pit in the whole construction process were studied through a numerical simulation for the excavation of a deep foundation pit of a $37 \mathrm{~m}$ deep city subway station with water-rich and locally broken intrusive rocks. The research results provide a reference for the excavation design and construction of deep foundation pits with water-rich and locally invaded broken diorite porphyritic stratum.

\section{General Situation of the Project}

The west side of the deep foundation pit of the line 4 subway station is adjacent to the Daedong River, and a scenic plaza and parking lot are present on the east side. This subway station is a $13 \mathrm{~m}$ island platform, double-column three-span station with four underground levels. The station is $158 \mathrm{~m}$ long, $26 \mathrm{~m}$ wide, and $37 \mathrm{~m}$ deep, and it is constructed using the open bottom-up method. The security level of the foundation pit is grade 1 .

2.1. Engineering Geological Conditions. According to the survey report, the pit area is mainly composed of a Holocene artificial accumulation layer, marine sedimentary layer, and alluvial layer. The underlying bedrock is late Yanshan granite, locally interspersed with diorite porphyrite, and the site area is still tectonically developing.

The artificial accumulation layer of the Fourth Series Holocene is filled with vegetation, and the marine sediment layer is mainly made of organic silt. These two layers have a loose structure and very poor homogeneity, poor selfstabilization ability after excavation, poor engineering properties, and strong permeability.

The alluvial-diluvial layer mainly consists of silty clay, organic silty clay, coarse sand, coarse gravel sand, and pebble. Silty clay is mainly malleable and partially malleable. Organic silty clay has high compressibility and low bearing capacity. The distribution of coarse sand is discontinuous and saturated. The bearing capacity is relatively low, and the excavation is prone to collapse and water gushing, coarse gravel sand saturation, and high bearing capacity. The bearing capacity of silty clay is relatively low. The pebble and bedrock have direct contact, saturation, high bearing capacity, and low compressibility.

The granites in the bedrock lie in the tectonic fracture zone and its influencing range; the borehole mostly exposes the sandy soil-like and massive cataclastic rocks. The bedrock of intrusive broken diorite porphyrite is affected by tectonic action joint development and crushing of rock mass; the joint surface mineral alteration is obvious, so the Aeolian zone rock mass quality classification is IV level.

The geological profile along this deep foundation pit is shown in Figure 1. It can be seen that at the beginning $0 \mathrm{~m}$, the elevation of medium coarse sand is $-2 \mathrm{~m}$. Near $40 \mathrm{~m}$ along the deep foundation pit, there are intrusive fractured porphyrites with an elevation of $-33 \mathrm{~m}$, and between $100 \mathrm{~m}$ and $110 \mathrm{~m}$ along the deep foundation pit, the elevation of medium coarse sand is $-13 \mathrm{~m}$.

2.2. Hydrogeological Condition. The site is located in the lower basin of the Daedong River, and the width of the river is about $80-90 \mathrm{~m}$. The bottom level of the river is about $0.77-$ $1.53 \mathrm{~m}$, and masonry embankments are present on both sides of the river, as shown in Figure 2. The river is a rain-sourced mountain stream-type river in the monsoon area, which is prone to flash floods during a heavy precipitation season. The critical daily precipitation of Daedong River flash flood was about $100 \mathrm{~mm}$, and the recurrence interval of flash flood is 2-3 years. Figure 1 shows that the water level of the deep foundation pit is $1.5-2.5 \mathrm{~m}$ below the ground.

The main types of groundwater in the pit area are quaternary pore water and bedrock fissure water. Quaternary pore water is divided into upper stagnant water and confined water; bedrock fissure water is mainly divided into weathered fissure water and structural fissure water. The upper stagnant water is mainly artificially filled with a soil layer, shallow silt, and sandy soil layer. The confined water aquifer is mainly composed of a sandy soil and gravel soil layer and also includes several clay-water resisting layer. Weathering fissure water is mainly stored in the bedrock's strong weathering to medium weathering zone rocks, which are sandy-soil, sandy, and gravelly. The weathered fissure development shows a 


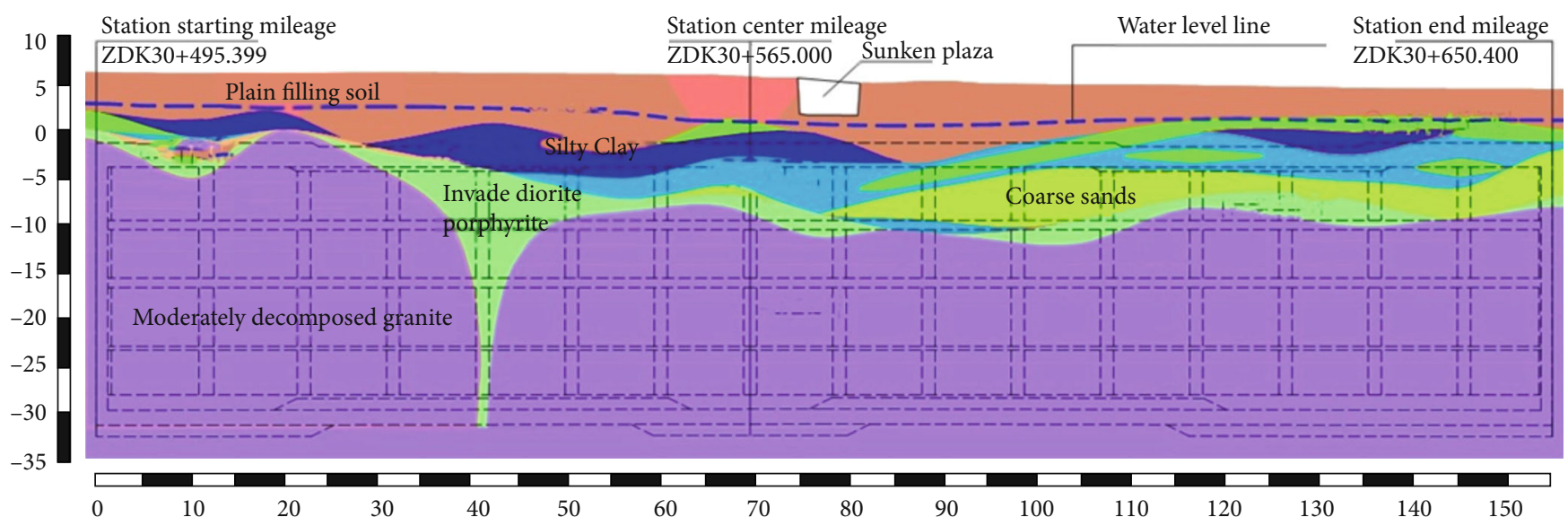

Figure 1: Geological profile along the deep foundation pit.

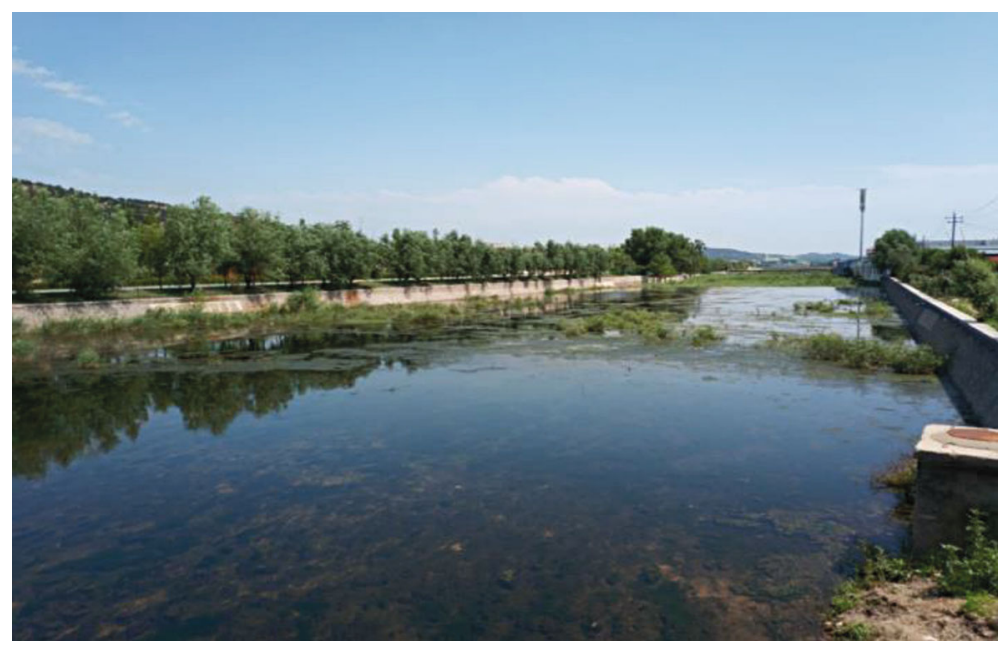

Figure 2: Daedong River.

layered distribution. The water surface is uniform, and the underground water level increases with the increase in the terrain. Because the bedrock's strong weathering zone and the upper quaternary aquifer have no stable continuous water barrier, the weathered fissure water has a certain hydraulic relationship with the pore water of a loose quaternary soil layer. The tectonic fissure water is mainly stored in the tectonic fissure zone of medium-weathered and slightly weathered bedrock and the dense zone of an extrusion fracture of late intruded vein-like rock veins, where it has a large depth of groundwater runoff, complex direction of runoff, and certain bearing pressure.

2.3. Design of Deep Foundation Pit Enclosure Structure. According to the design document, the deep foundation pit retaining system consists of three parts, as shown in Figure 3. The underground diaphragm wall and internal support are used in the first part of the ground to $15 \mathrm{~m}$ underground. The second part uses steel pipe piles and prestressed anchors from $15 \mathrm{~m}$ underground to $37 \mathrm{~m}$ at the bottom of the pit. In the third part, a concrete uplift pile and concrete cushion are applied at the bottom of the foundation pit. The specific design is as follows:
Part I of the Enclosure System. The first one uses a concrete inner support and crown beam, and the remaining four inner supports use a double 56C I-beam and an $800 \mathrm{~mm}$ steel pipe. The foundation pit column uses a $1400 \mathrm{~mm} \times 1000 \mathrm{~mm}$ concrete pile. The depth of the underground diaphragm wall is $15 \mathrm{~m}$ and penetrates the underground rock mass for about 3$5 \mathrm{~m}$. The waterproof curtain lies on the underground diaphragm wall.

Part II of the Enclosure System. After the construction of the underground diaphragm wall was completed, a $25 \mathrm{~m}$ long steel pipe pile with a diameter of $200 \mathrm{~mm}$ was embedded in the rock with a spacing of $900 \mathrm{~mm}$. After the construction of steel pipe piles was completed, the prestressing anchors were started. Eleven layers of prestressing anchors were installed with a vertical spacing of $2 \mathrm{~m}$ and lateral spacing of $1.8 \mathrm{~m}$. Then, $700 \mathrm{kN}$ of prestressing was applied to the 1-4 layers, $500 \mathrm{kN}$ to the $5-8$ layers, and $200 \mathrm{kN}$ to the 9-11 layers.

Part III of the Enclosure System. After the excavation of the foundation pit was completed, eight rows of concrete uplift piles with a lateral spacing of $3 \mathrm{~m}$, a length of $4 \mathrm{~m}$, and a diameter of $400 \mathrm{~mm}$ were placed in the bottom of the foundation pit, finally laying a $200 \mathrm{~mm}$ thick concrete bedding layer. 


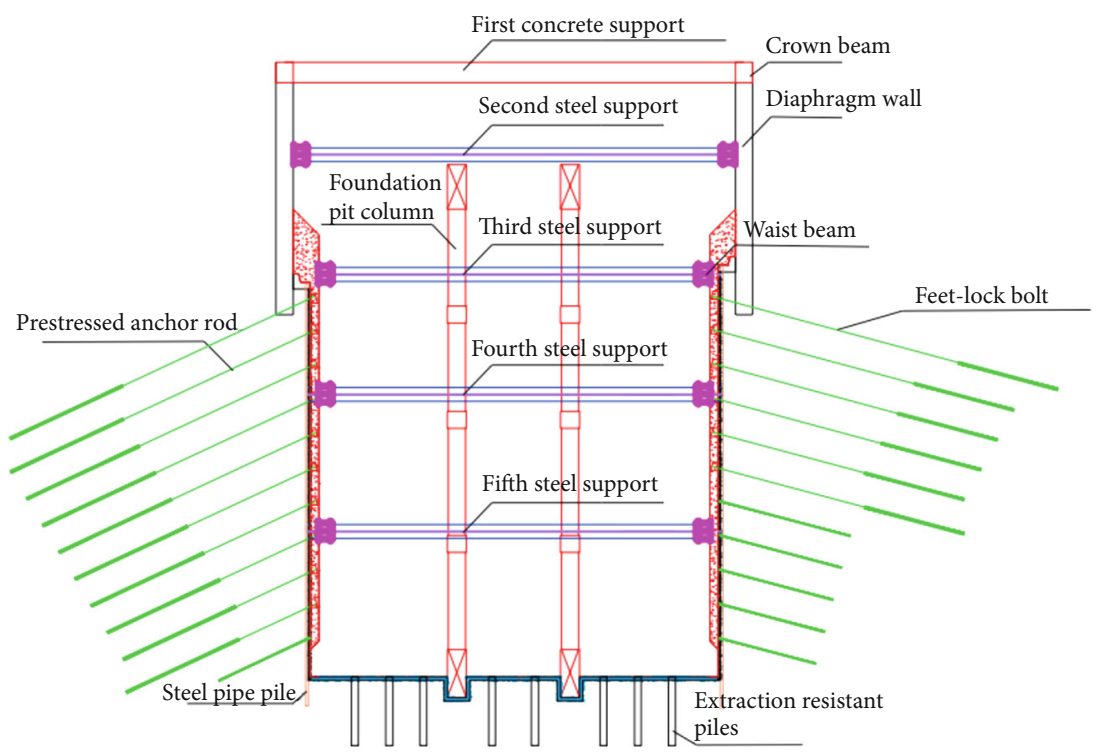

FIGURE 3: Enclosure system of the deep foundation pit.

\section{Seepage Field and Deformation Characteristics of the Deep Foundation Pit}

Currently, urban underground projects in China are more often designed using MIDAS software, which is developed in the Visual C++ language of the Windows system. It is a software program for the stress and infiltration analysis and design in the construction phase of geotechnical structures. In this study, MIDAS/GTS software was used for simulation analysis, and the geotechnical parameters and material properties used in the simulation were provided from the design file of the deep foundation pit, so that the simulation results can reflect the seepage and deformation characteristics of the deep foundation pit under the design of the deep foundation pit and better guide the design.

\subsection{MIDAS Numerical Model Simulation}

3.1.1. Basic Theory of MIDAS Seepage Analysis. MIDAS seepage analysis includes steady-flow analysis and unsteady-flow analysis [29]. In this study, unsteady-flow analysis was used to establish the model. The flow law used in MIDAS/GTS is Darcy's law, and the formula of penetration flow per unit area is as follows:

$$
q=k i
$$

where $q$ is the seepage discharge per unit area, $k$ is the permeability coefficient, and $i$ is the hydraulic gradient.

It is assumed that the change in the inflow and outflow of a small volume at any position and at any time is the same as the change in the volume moisture content. Simply put, the change of flow in the $x, y$, and $z$ directions is the same as the change of the sum of the flows and the volumetric moisture content.
The basic equation for flow is as follows:

$$
\frac{\partial}{\partial x}\left(k_{x} \frac{\partial H}{\partial x}\right)+\frac{\partial}{\partial y}\left(k_{y} \frac{\partial H}{\partial y}\right)+\frac{\partial}{\partial z}\left(k_{z} \frac{\partial H}{\partial z}\right)+Q=\frac{\partial \Theta}{\partial t}
$$

where $H$ is the total head; $k_{x}, k_{y}$, and $k_{z}$ are the permeability coefficient in the $x, y$, and $z$ directions, respectively; $Q$ is the flow rate; $\Theta$ is the volumetric water content; and $t$ is the time.

According to Darcy's law, the laminar velocity is very small, so the velocity head can be ignored. The total head can be regarded as the sum of pressure head and position head.

$$
H=\frac{u_{\mathrm{w}}}{\gamma_{\mathrm{w}}}+z
$$

where $u_{\mathrm{w}}$ is the pore water pressure, $\gamma_{\mathrm{w}}$ is the unit weight of water, and $z$ is the elevation.

3.1.2. Establishment of the Numerical Model. The construction phase of deep foundation pits was modelled using the MIDAS/GTS software. The actual excavation part of the deep foundation pit in this project is $158 \mathrm{~m}$ long, $26 \mathrm{~m}$ wide, and $37 \mathrm{~m}$ deep. Considering the boundary conditions, the whole numerical model is $299 \mathrm{~m}$ long, $167 \mathrm{~m}$ wide, and $55 \mathrm{~m}$ deep. There are 125248 nodes and 248745 elements in the whole model. The physical and mechanical parameters of each soil layer are shown in Table 1. At present, the pit is under construction and has been excavated to $8 \mathrm{~m}$. Combined with the site monitoring data, the geotechnical parameters shown in Table 1 are consistent with the site monitoring data. The numerical model is shown in Figure 4. The Mohr-Coulomb constitutive model was used in the soil layer of modulus value type. Crown beam, lumbar beam, and steel internal support all used the beam element. This is because the displacement of the uplift pile and pit column in the vertical direction is restrained, and their force characteristics are similar to those 
TABle 1: Physical and mechanical parameters of surrounded layers.

\begin{tabular}{|c|c|c|c|c|c|c|c|}
\hline Soil layer & $\begin{array}{l}\text { Thickness } \\
(\mathrm{m})\end{array}$ & $\begin{array}{l}\text { Elastic modulus } \\
(\mathrm{MPa})\end{array}$ & $\begin{array}{l}\text { Poisson's } \\
\text { ratio } \mu\end{array}$ & $\begin{array}{c}\gamma \\
\left(\mathrm{kN} \cdot \mathrm{m}^{-3}\right)\end{array}$ & $\begin{array}{l}\text { Permeability coefficient } \\
(\mathrm{m} \cdot \mathrm{d})\end{array}$ & $\begin{array}{c}\text { Cohesion } \\
(\mathrm{kPa})\end{array}$ & $\begin{array}{c}\text { Internal friction angle } \\
\varphi\left({ }^{\circ}\right)\end{array}$ \\
\hline Plain fill & 5 & 0.3 & 0.17 & 18 & 30 & 10 & 20 \\
\hline Silty clay & 4 & 50 & 0.33 & 20 & 0.02 & 34.9 & 16.5 \\
\hline Coarse sand & 7 & 18 & 0.3 & 20.5 & 15 & 0.1 & 30 \\
\hline $\begin{array}{l}\text { Fractured } \\
\text { rock }\end{array}$ & 10 & 12000 & 0.2 & 25 & 0.5 & 5000 & 50 \\
\hline Granite & 30 & 30000 & 0.1 & 26 & 0.001 & 30000 & 60 \\
\hline
\end{tabular}

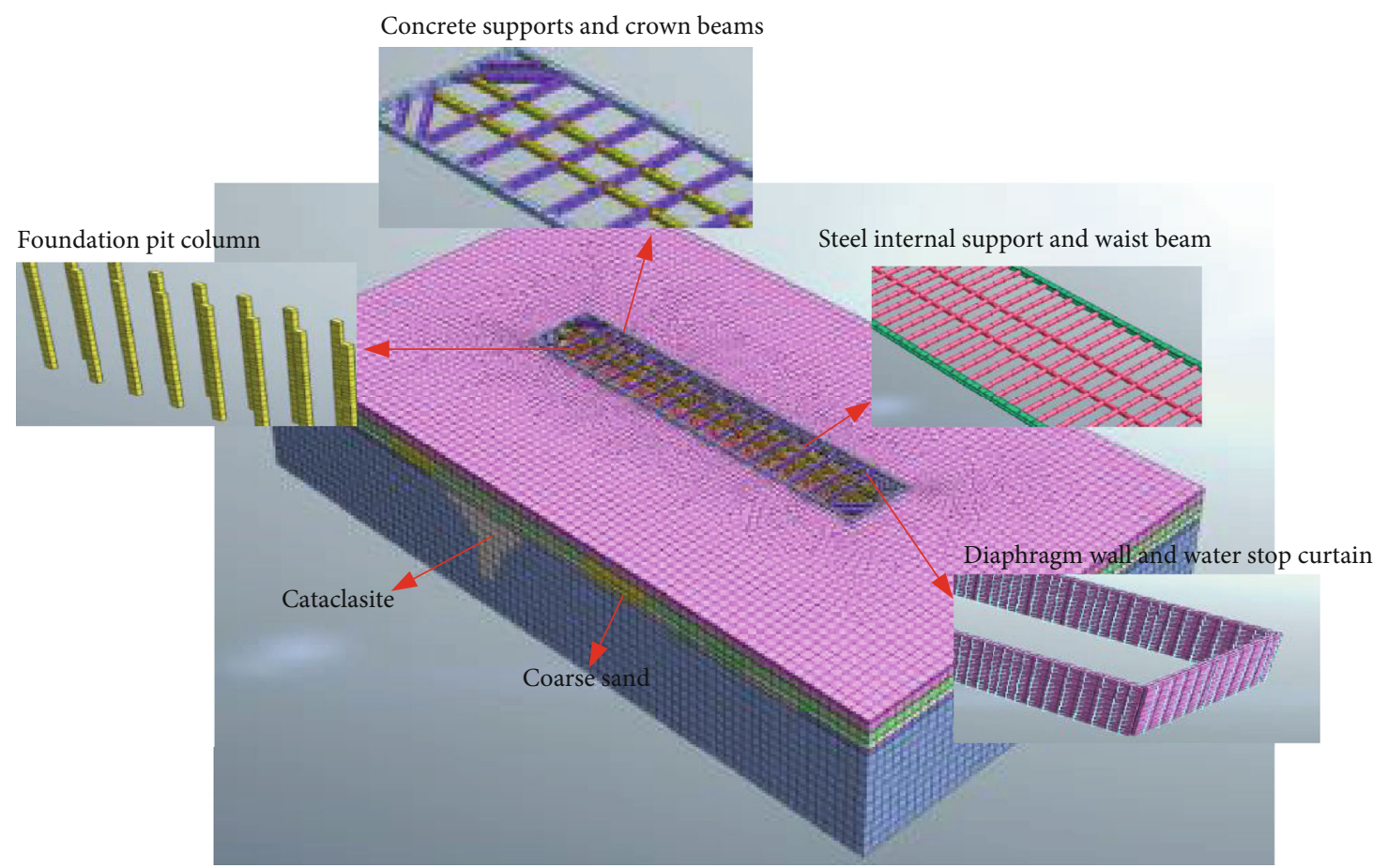

FIGURE 4: MIDAS/GTS numerical simulation diagram.

of the beam. Therefore, they also use the beam element. The foundation pit floor and underground diaphragm wall were simulated with the plate element. When establishing the waterproof curtain on the underground diaphragm wall because the waterproof curtain belongs to the interface element which is equivalent to cutting the nodes, it will cause the nodes to be uncoupled. Therefore, before the underground diaphragm wall is activated with the waterproof curtain, a rigid connection should be established to bind the cut nodes together to make the model coupled as a whole body. Prestressing anchors were used using the implanted truss element.

(1) Boundary Conditions of Model Displacement. The normal displacement around the model and surface is constrained, and the top surface is the free surface. The seepage boundary condition is the impermeable boundary at the place where the continuous underground diaphragm wall is precipitated around the foundation pit. The permeability coefficient is $0 \mathrm{~m} / \mathrm{d}$ at the place where the waterproof curtain is set. However, in the excavation of the pit to $15 \mathrm{~m}$ below, the excavation was carried out deep into the rock layer. Because the perme- ability coefficient is very small, the actual project did not set the waterproof curtain. However, the project section has the possibility of infiltration of groundwater outside the pit. For example, under about $10 \mathrm{~m}$ underground, a section of sandy fractured rock with a large permeability coefficient invaded the granite interior. This section is very likely to allow underground water from outside the pit flow into the pit.

3.1.3. Deep Foundation Pit Construction Phase. The simulation of the deep foundation pit construction phase is shown in Figure 5. The excavation of this deep foundation pit is divided into six steps. The precipitation is divided into six steps. Five supports were applied. Prestressed anchors were applied after the excavation of the $4^{\text {th }}$ step of precipitation, and finally, the uplift piles and the foundation slab were applied.

3.2. Seepage Field Characteristics. The seepage path and corresponding pore water pressure of the deep foundation pit after six precipitation events were extracted, as shown in Figure 6 . The seepage path of the deep foundation pit after each precipitation is different. Intrusive broken diorite 


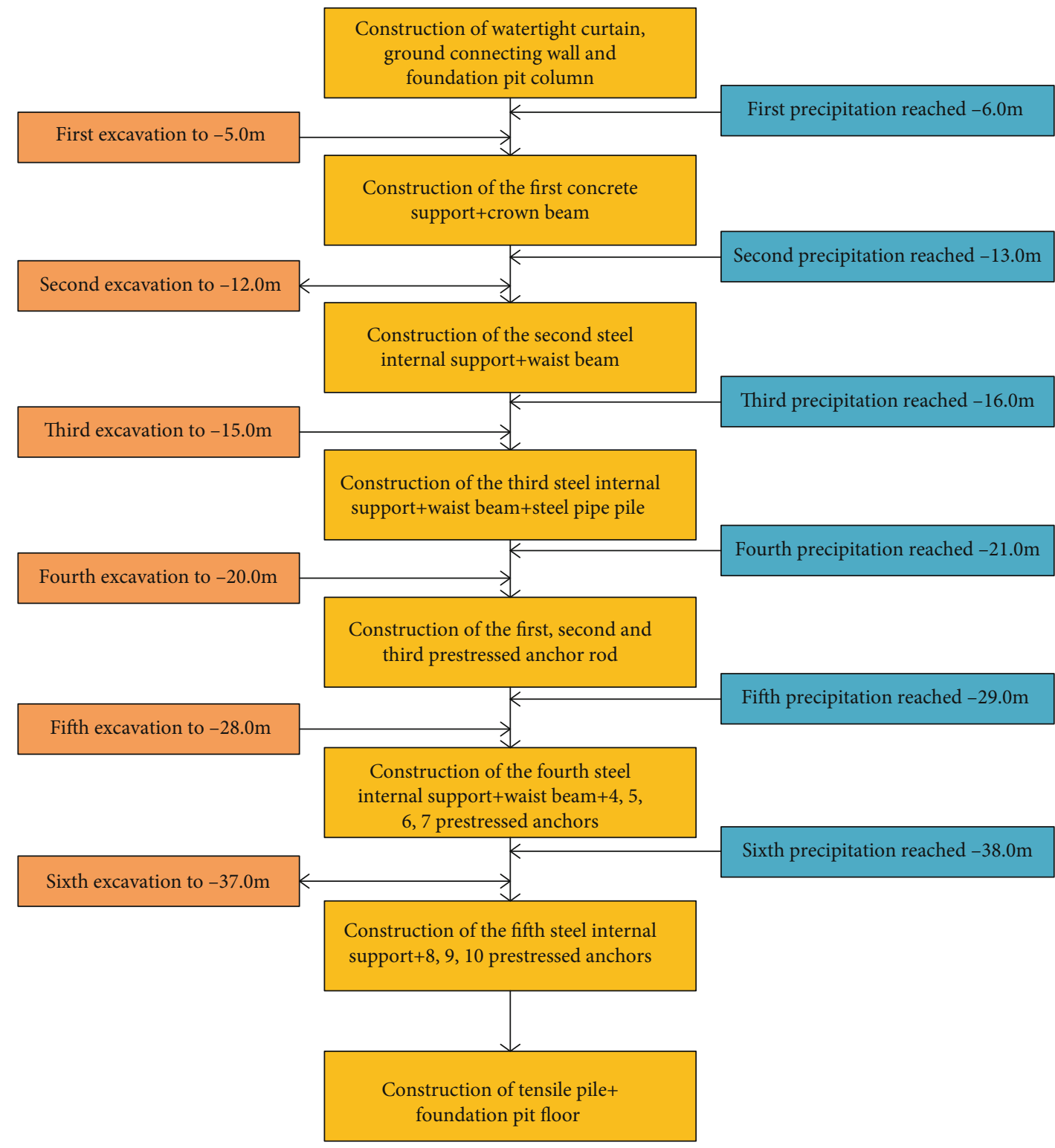

FIGURE 5: Deep foundation pit construction phase.

porphyrite and medium coarse sand are the key points and belts for waterproofing the deep foundation pit. With the precipitation-excavation of the deep foundation pit, the pore water pressure at the bottom of the foundation pit shows a distribution of three "concave" shapes. A high-permeability pressure zone occurs around the foundation pit, the intrusive broken diorite porphyrite zone, and the middle coarse sand zone. With further excavation of the foundation pit, the seepage pressure in the middle of the foundation pit gradually decreases, and the two "concave" shapes in the middle of the foundation pit gradually merge together. After excavation to the bottom of the foundation pit, the pore water pressure at the bottom of the foundation pit shows two asymmetrical "concave" shapes, and the peak value is located at the place where broken diorite porphyrite is intruded, which is prone to water inrush. The four corners of the foundation pit are prone to seepage accumulation and subduction corrosion and finally form the piping zone.
Figure $6(\mathrm{a})$ shows the seepage path of the $1^{\text {st }}$ precipitation and the distribution of pore water pressure at the bottom of the pit. Three seepage gathering points are present in the deep foundation pit. Two of them are at the corners of the pit on both sides of the pit, and the stratum above them is medium-coarse sand. The other one is intrusive broken diorite porphyrite area. Although there are three seepage accumulation points, the height of the foundation pit seepage path at this time only reaches the silty clay layer, and the pore water pressure of the foundation pit floor shows negative pressure.

Figure 6(b) shows the seepage path of the $2^{\text {nd }}$ precipitation and the distribution of pore water pressure at the bottom of the pit. The height of the seepage path of the deep pit only reaches the silted clay layer, and the pore water pressure at the bottom of the pit slightly varies with the positive pore water pressure at the bottom of the pit.

Figure 6(c) shows the seepage path of the $2^{\text {nd }}$ precipitation and the distribution of pore water pressure at the bottom 


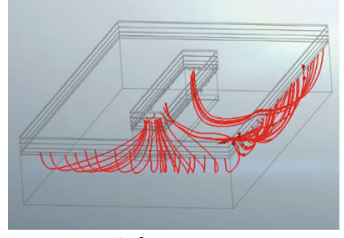

Side view

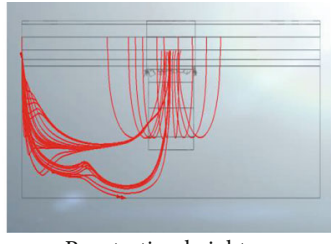

Penetration height

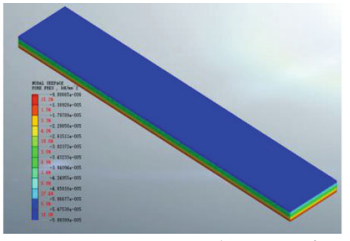

Pore water pressure at bottom of pit

(a) Seepage path and pore water pressure distribution at the bottom of the pit of the $1^{\text {st }}$ precipitation

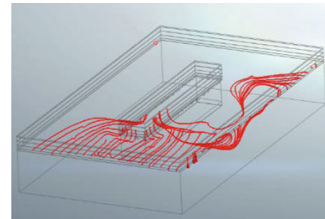

Side view

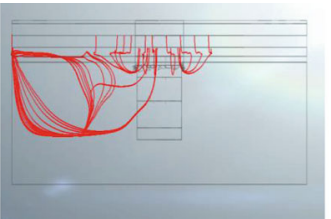

Penetration height

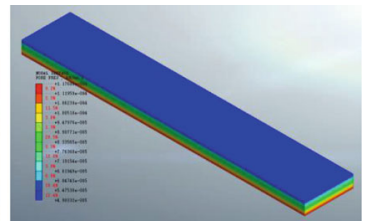

Pore water pressure at bottom of pit

(b) Seepage path and pore water pressure distribution at the bottom of the pit of the $2^{\text {nd }}$ precipitation

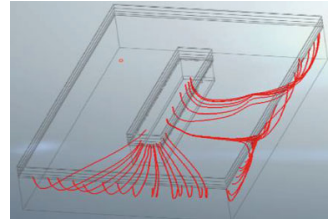

Side view

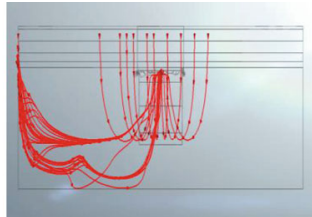

Penetration height

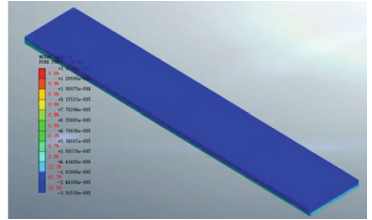

Pore water pressure at bottom of pit

(c) Seepage path and pore water pressure distribution at the bottom of the pit of the $3^{\text {rd }}$ precipitation

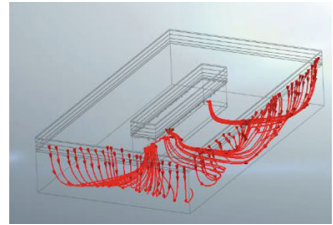

Side view

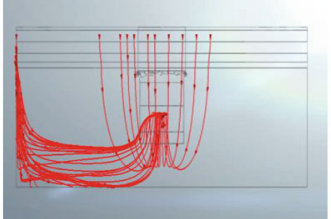

Penetration height

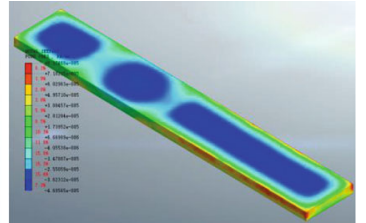

Pore water pressure at bottom of pit

(d) Seepage path and pore water pressure distribution at the bottom of the pit of the $4^{\text {th }}$ precipitation

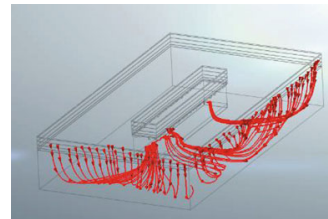

Side view

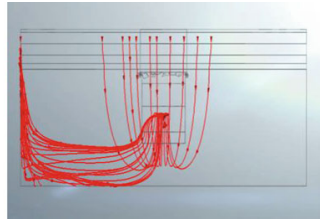

Penetration height

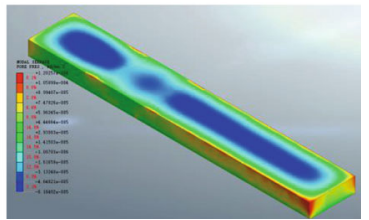

Pore water pressure at bottom of pit

(e) Seepage path and pore water pressure distribution at the bottom of the pit of the $5^{\text {th }}$ precipitation

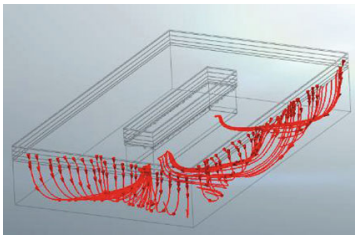

Side view

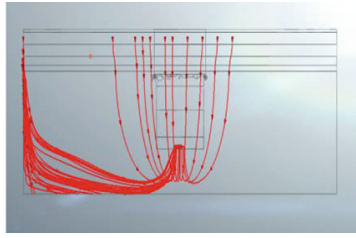

Penetration height

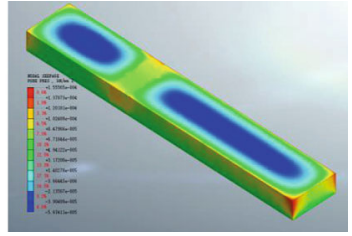

Pore water pressure at bottom of pit

(f) Seepage path and pore water pressure distribution at the bottom of the pit of the $6^{\text {th }}$ precipitation

FigURE 6: Seepage path and pore water pressure evolution of the deep foundation pit after precipitation.

of the pit. When the deep foundation pit is excavated to about $15 \mathrm{~m}$ underground, i.e., when the diaphragm wall and steel pipe pile are converted, the maximum pore water pressure at the bottom of the pit is $135 \mathrm{kN} / \mathrm{m}^{2}$. It is highly recommended to make waterproof work before continuing the construction.
Figure $6(\mathrm{~d})$ shows the seepage path of the $2^{\text {nd }}$ precipitation and the distribution of pore water pressure at the bottom of the pit. The seepage path of the deep foundation pit became more and more concentrated, and the pore water pressure is distributed in 3 "concave" shapes at the bottom of excavation. High-permeability pressure zones are present 


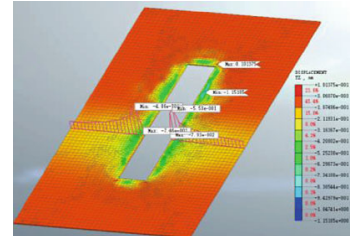

Surface settlement

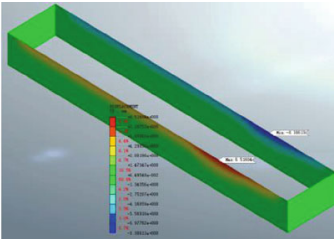

Underground diaphragm wall convergence

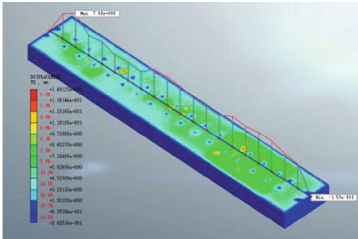

Uplifts of foundation pit

(a) Deformation characteristics of the $1^{\text {st }}$ precipitation excavation

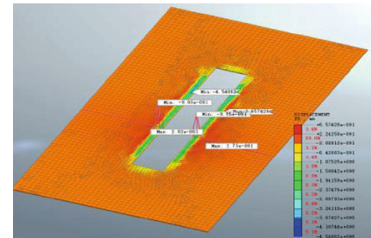

Surface settlement

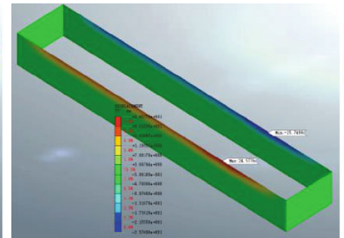

Underground diaphragm wall convergence

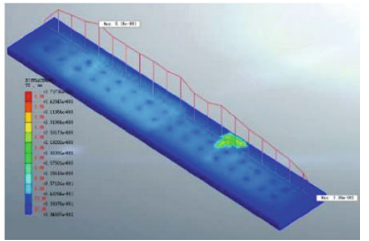

Uplifts of foundation pit

(b) Deformation characteristics of the $1^{\text {st }}$ precipitation excavation

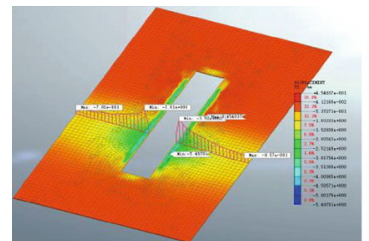

Surface settlement

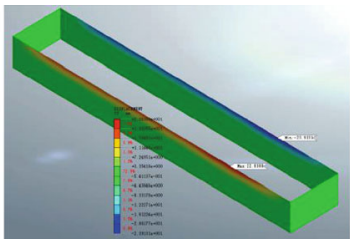

Underground diaphragm wall convergence

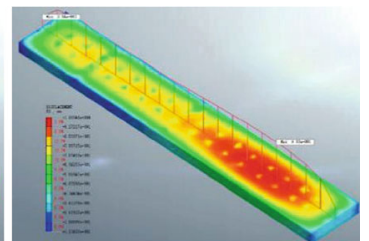

Uplifts of foundation pit

(c) Deformation characteristics of the $1^{\text {st }}$ precipitation excavation

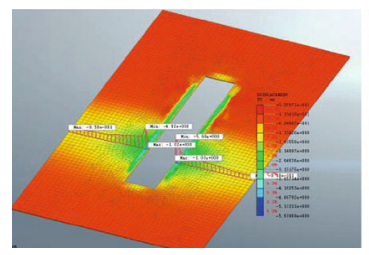

Surface settlement

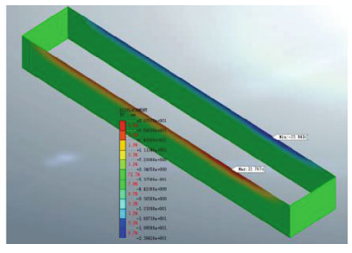

Underground diaphragm wall convergence

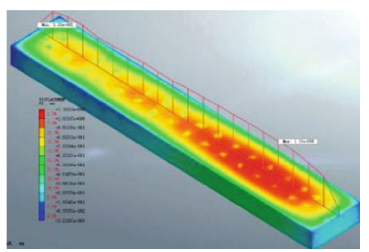

Uplifts of foundation pit

(d) Deformation characteristics of the $1^{\text {st }}$ precipitation excavation

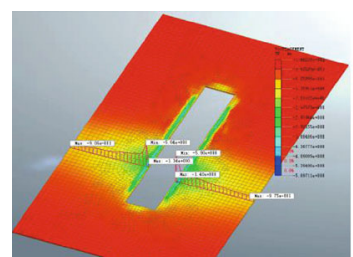

Surface settlement

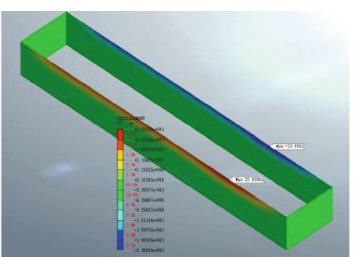

Underground diaphragm wall convergence

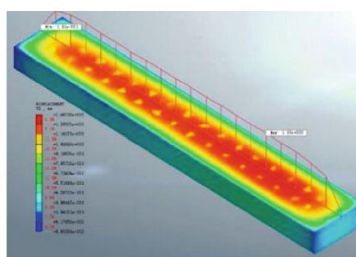

Uplifts of foundation pit

(e) Deformation characteristics of the $1^{\text {st }}$ precipitation excavation

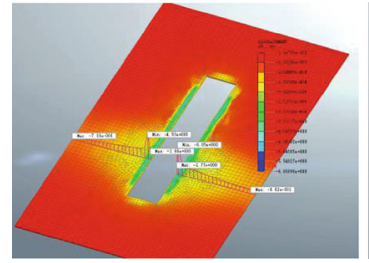

Surface settlement

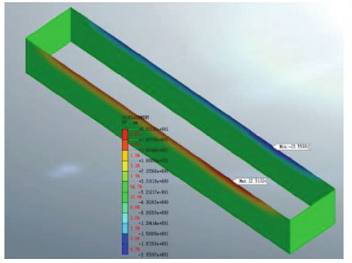

Underground diaphragm wall convergence

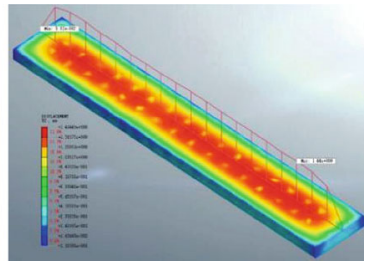

Uplifts of foundation pit

(f) Deformation characteristics of the $1^{\text {st }}$ precipitation excavation

FIGURE 7: Deformation evolution of deep foundation pit precipitation excavation. 
around the foundation pit, the intrusive broken diorite porphyrite zone, and the middle coarse sand zone.

Figure $6(\mathrm{e})$ shows the seepage path of the $2^{\text {nd }}$ precipitation and the distribution of pore water pressure at the bottom of the pit. Although the pore water pressure is still distributed in three "concave" shapes at the bottom of the pit at the excavation, the two "concave" shapes between the intrusive broken diorite porphyrite and the terminal mile of pit tend to merge together.

Figure $6(\mathrm{f})$ shows the seepage path of the $2^{\text {nd }}$ precipitation and the distribution of pore water pressure at the bottom of the pit. After the end of precipitation, the pore water pressure at the bottom of the pit showed two very obvious "concave" shapes, mainly due to the presence of intrusive broken diorite porphyrite in the deep pit, which changed the groundwater flow path of pit excavation and showed multiple "concave" patterns.

3.3. Deformation Characteristics. Figure 7 shows the deformation evolution of deep foundation pit precipitation. The surface settlement caused by excavation is the largest along the longitudinal axis of the deep foundation pit in the area invaded by the broken zone, and the largest deformation along the horizontal axis of the foundation pit was found near the foundation pit side. After the excavation of the foundation pit entered the moderately weathered rock stratum, the surface settlement became stable. With the excavation of the deep foundation pit, the convergence deformation of the underground diaphragm wall to the pit occurred, with a maximum value of about $25 \mathrm{~mm}$. The change in the underground diaphragm wall was only above the construction of the medium weathering rock layer. With the construction of steel pipe piles, the deformation of the underground diaphragm wall became stable. After the first precipitation excavation of the deep foundation pit to the powder clay, the bottom of the pit had an uplift to the maximum. With further precipitation-excavation, the uplift of the bottom had only a small change.

\section{Conclusion}

Based on a project of a deep foundation pit in a subway station, the characteristics of groundwater flow path evolution and deformation field during the whole process of deep foundation pit precipitation excavation with water-rich intrusive broken diorite porphyrite were simulated using a numerical simulation method, and the conclusions are as follows:

(1) Intrusive broken diorite porphyrite and medium coarse sand are the key points and belts for waterproofing a deep foundation pit. High-permeability pressure zones are present around the foundation pit, the intrusive broken diorite porphyrite zone, and the middle coarse sand zone. Water inrush easily occurs in the place of broken diorite porphyrite. The four corners of the foundation pit are prone to seepage accumulation and subduction corrosion and finally form the piping zone
(2) The pore water pressure at the bottom of the deep foundation pit gradually shows a distribution of three "concave" shapes with the excavation of precipitation. With further excavation, the seepage pressure in the middle part of the pit gradually decreases, and the two "concave" shapes in the middle gradually merge together. After excavation to the bottom of the pit, the pore water pressure in the bottom of the pit is asymmetrically distributed in two "concave" shapes

(3) The surface settlement caused by deep foundation pit excavation is the largest along the longitudinal axis of the deep foundation pit in the intruding and crushing zone. In the horizontal axis direction of the foundation pit, it is the largest near the side of the foundation pit, and the surface settlement at one time of the excavation depth is approximately 0 . The surface settlement becomes stable after the foundation pit excavation reaches the moderately weathered rock stratum

(4) With the excavation of the deep foundation pit, the convergence deformation of the diaphragm wall towards the interior of the foundation pit occurs, and the maximum value of convergence deformation is about $25 \mathrm{~mm}$. The change in the underground diaphragm wall was only above the construction of medium weathering rock layer. With the construction of steel pipe piles, the convergence deformation of the underground diaphragm wall becomes stable

(5) After the first precipitation excavation of the deep foundation pit to silty clay, the uplift at the bottom of the pit is the largest, but with further precipitation-excavation, the uplift only changes slightly

\section{Data Availability}

The data supporting the results of our study are included within the manuscript.

\section{Conflicts of Interest}

The authors declare no conflict of interest.

\section{Acknowledgments}

This study is supported by the Natural Science Foundation of Shandong Province (ZR2017MEE017), Key R\&D Project of Shandong Province (Public Welfare Projects) (2018GSF120005), and National Natural Science Foundation of China (51174124).

\section{References}

[1] Chinese Institution of Soil Mechanics and Geotechnical Engineering, "Guide to deep excavation support," p. 8, 2012.

[2] H. J. Su, Y. J. Feng, Q. Z. Guo, H. W. Jing, W. X. Zhu, and Q. Yin, "Model experimental study on the seepage and failure features of tunnel under wetting-drying alternation with increasing water pressure," Geofluids, vol. 5, 11 pages, 2020. 
[3] B. B. Xi, X. Q. Zhang, Z. Yan et al., "Analysis of seepage field characteristics of tunnel foundation pit under different depths of waterproof curtain," Journal of Lanzhou Institute of Technology, vol. 27, no. 1, pp. 24-27, 2020.

[4] M. M. Qiu, G. L. Yang, Q. Shen, J. Y. Duan, and P. R. Zhang, "Deformation characteristics of foundation pit excavation under the combined action of diaphragm wall and impervious curtain in water-rich sandy stratum," Journal of Yangtze River Scientific Research Institute, vol. 37, no. 11, pp. 81-88, 2020.

[5] C. F. Yuan, Z. J. Yuan, Y. T. Wang, and C. M. Li, "Analysis of the diffusion process of mining overburden separation strata based on the digital speckle correlation coefficient field," International Journal of Rock Mechanics and Mining Sciences, vol. 119, pp. 13-21, 2019.

[6] Z. Li, H. X. Liu, Z. L. Dun, L. W. Ren, and J. J. Fang, "Grouting effect on rock fracture using shear and seepage assessment," Construction and Building Materials, vol. 242, article 118131, 2020.

[7] Z. Li, S. G. Liu, W. T. Ren, J. J. Fang, Q. H. Zhu, and Z. L. Dun, "Multiscale laboratory study and numerical analysis of waterweakening effect on shale," Advances in Materials Science and Engineering, vol. 2020, Article ID 5263431, 14 pages, 2020.

[8] Q. Meng, H. Wang, M. Cai, W. Xu, X. Zhuang, and T. Rabczuk, "Three-dimensional mesoscale computational modeling of soil-rock mixtures with concave particles," Engineering Geology, vol. 277, article 105802, 2020.

[9] H. Cai, Z. J. Yang, L. Y. Wang et al., "An experimental study on the hydromechanical behaviours of the evolution of postearthquake landslide deposits," Geofluids, vol. 6, 18 pages, 2019.

[10] A. S. Cong, "Discussion on several issues of seepage stability of deep foundation pit in multilayered formation," Chinese Journal of Rock Mechanics and Engineering, vol. 28, no. 10, pp. 2018-2023, 2009.

[11] C. Zhu, M. C. He, M. Karakus, X. B. Cui, and Z. Tao, "Investigating toppling failure mechanism of anti-dip layered slope due to excavation by physical modelling," Rock Mechanics and Rock Engineering, vol. 53, no. 11, pp. 5029-5050, 2020.

[12] Y. Wang, B. Zhang, S. H. Gao, and C. H. Li, "Investigation on the effect of freeze-thaw on fracture mode classification in marble subjected to multi-level cyclic loads," Theoretical and Applied Fracture Mechanics, vol. 111, article 102847, 2021.

[13] Q. Hu, D. S. Ling, R. P. Chen, Y. M. Chen, and G. W. Jia, "Research on deep foundation pit excavation due to seepage failure of soil," Chinese Journal of Rock Mechanics and Engineering, vol. 29, no. 11, pp. 2967-2972, 2008.

[14] L. T. Chen, D. Zhu, C. Yang, Y. T. Zeng, and C. J. Xu, "Influence of waterproof curtain on the deformation control of deep foundation pit dewatering and excavation," Journal of Civil and Environmental Engineering, pp. 1-9, 2020.

[15] P. Gong, X. Y. Ni, Z. Q. Chen, Y. Wu, J. Y. Wu, and B. J. Bai, "Experimental investigation on sandstone permeability under plastic flow: permeability evolution law with stress increment," Geofluids, vol. 2, 19 pages, 2019.

[16] C. Zhu, X. D. Xu, and W. R. Liu, "Softening damage analysis of gypsum rock with water immersion time based on laboratory experiment," IEEE Access, vol. 7, pp. 125575-125585, 2019.

[17] C. Zhu, Z. Yan, Y. Lin, F. Xiong, and Z. Tao, "Design and application of a monitoring system for a deep railway foundation pit project," IEEE Access, vol. 7, pp. 107591-107601, 2019.

[18] Q. Zhang, A. N. Jing, S. Zheng, S. J. Zheng, and R. Yang, "Fluid-structure coupling analysis of foundation pit excavation near underground culverts based on ZSI," Chinese Journal of Underground Space and Engineering, vol. 14, pp. 803-812, 2018.

[19] Y.S. Wang and W. H. Chen, "Research on criterion of seepage failure for deep foundation pit with diaphragm wall defects," Chinese Journal of Underground Space and Engineering, vol. 15, pp. 951-958, 2019.

[20] Z. B. Lin, B. Y. Zhang, and D. F. Yang, "Simulation study on foundation pit excavation in soft soil considering effect of creep and seepage," Modern Tunnelling Technology, vol. 57, no. 1, pp. 91-98, 2020.

[21] Y. D. He, "Deformation law and stability of foundation pit considering seepage effect," Journal of Water Resources and Architectural Engineering, vol. 18, no. 1, pp. 28-31, 2020.

[22] D. W. Yin, S. J. Chen, Y. Ge, and R. Liu, "Mechanical properties of rock-coal bi-material samples with different lithologies under uniaxial loading," Journal of Materials Research and Technology, vol. 10, pp. 322-338, 2021.

[23] M. N. Wang, Z. Q. Zeng, Y. T. Jiang, and D. G. Liu, "Upper limit analysis of continuous deformation field infiltration force on anti - uplift instability of foundation pit," Journal of Railway Engineering Society, vol. 17, pp. 12-18, 2019.

[24] C. Zhu, M. C. He, Q. Yin, and X. H. Zhang, "Numerical simulation of rockfalls colliding with a gravel cushion with varying thicknesses and particle sizes," Geomechanics and Geophysics for Geo-Energy and Geo-Resources, vol. 7, pp. 1-11, 2021.

[25] C. Shi, S. N. Wang, L. Liu, Q. X. Meng, and Q. Zhang, "Mesomechanical simulation of direct shear test on outwash deposits with granular discrete element method," Journal of Central South University, vol. 20, no. 4, pp. 1094-1102, 2013.

[26] L. Yan, Q. X. Meng, W. Y. Xu et al., "A numerical method for analyzing the permeability of heterogeneous geomaterials based on digital image processing," Journal of Zhejiang University-SCIENCE A, vol. 8, no. 2, pp. 124-137, 2017.

[27] Z. S. Liang, "Analysis and numerical simulation on the coupling between3-D stress field and seepage field during deep excavation," Journal of Yangtze River Scientific Research Institute, vol. 31, no. 5, pp. 79-83, 2014.

[28] A. Pazdniakou, M. Dymitrowska, and I. Clark, "Migration of gas in water saturated clays by coupled hydraulic-mechanical model," Geofluids, vol. 2018, 25 pages, 2018.

[29] MIDAS Geotechnical, Tunnel Analysis System, MIDAS Information Technology China Co., Ltd., 2014. 